\title{
The Change of Heterosexual Preference in Adolescents: Implications of Stress and Cognitive Regulation on Sexual Orientation
}

\author{
Binggen Zhu ${ }^{1,2^{*}}$, Xiaodan Ren ${ }^{1 *}$, Jing $\mathrm{Cao}^{1}$, Yujie Wu${ }^{1}$, Rongshen Zhu ${ }^{1}$ \\ ${ }^{1}$ The Department of Psychiatry at Shanghai Tenth People's Hospital, \\ Tongji University School of Medicine, Shanghai, China \\ ${ }^{2}$ Departmet of Physiology, Tongji University School of Medicine, Shanghai, China \\ Email: binggen.zhu@tongji.edu.cn
}

Received October 2013

\begin{abstract}
Sexual orientation is a complex area. It is unclear to date how people precisely establish their preferred sexual objects. This paper presents two cases, whose heterosexual preference were changed in late adolescent age after a severe psychological event, to draw attention to the study of the possible underlying mechanism. Case 1, one identical male twin, was seriously punished at age 12 years, as he loved a girl in his classroom. Afterwards, he feared to contact with girls, and became attracted to young men at age 17 years, and kept same-sex sexual behaviors since then. However, his twin brother is always heterosexual. Case 2, a girl at age 16 years, was unexpectedly betrayed by her boyfriend, she bore great pain and distress in the beginning. Since then, she had a definite opinion that men were unbelievable, and gradually turned her heterosexual preference and had same-sex sexual behaviors with a girl classmate more than 3 years. Our case presentation indicates that severe frustration of primary heterosexual desires or behaviors and the successive cognitive regulation might lead susceptible adolescents into reorienting their sexual preference. The role of prefrontal cortex and related neuromodulatory pathways were discussed.
\end{abstract}

Keywords: Adolescents; Sexual Orientation; Sexual Preference; Stress; Cognitive Regulation

\section{Introduction}

Sexual orientation is a complex area (Rubio-Aurioles \& Wylie, 2008). It is unclear to date how people precisely establish their preferred sexual objects, although many researchers signify the contributions of sex steroid hormones, sex chromosome genes, and environment and socialization factors (Arnold, 2009; Corsello et al., 2011; Garcia-Falgueras \& Swaab, 2010; Hines, 2011). The differentiation of sex-specific gonads determined by the function of sex chromosone genes is a primary step in the physiological development of sex (Blecher \& Erickson, 2007; DiNapoli \& Capel, 2008). Then, sex-specific traits (including structures and functions) in nongonadal tissues are determined by sex steroids (e.g. testosterone and estrogen) secreted from the developing gonads, according to an absolute hormonal determinism (Arnold, 2009; Garcia-Falgueras \& Swaab, 2010). Fetal exposure to sex steroids particularly plays a major organizing influence on the expression of later sexual dimorphism (Arnold, 2009). But the hypothesis of hormonal determinism has been challenged. There are good evidences suggesting that the cell-autonomous information directly provided by sex chromosome genes, but unrelated to gonadal hormones, participates in the establishment of tissue sex differentiation (Arnold, 2009; Bocklandt \& Vilain, 2007). Moreover, after birth, in addition that the early and pubertal surges of testosterone or estrogen continue to play organizing/activating roles in sex-specific body and behavioral development (Berenbaum \& Beltz, 2011), environment and socialization factors gain importance (Corsello et al., 2011; Hines, 2011; Joel, 2011).

\footnotetext{
*Binggen Zhu and Xiaodan Ren contributed equally to this work.
}

Parents/caregivers and then peers usually encourage children to develop in their physiological gender-type way, guiding by the widely-recognized psychological characteristics of sexual dimorphism.

Some of brain structures are found to exhibit sexual dimorphism, which is presumably related to sexual orientation (Herbert, 2008; Savic \& Lindstrom, 2008). Many researchers pointed to the third interstitial nucleus of the anterior hypothalamus, because it is 2.5 times larger in men than in women, and this volume difference in other mammals results from prenatal testosterone exposure (Herbert, 2008; Savic, Garcia-Falgueras, \& Swaab, 2010). Moreover, patterns of cerebral asymmetry and functional brain connectivity/network are also linked to sexual orientation in men and women (Savic \& Lindstrom, 2008; Corsello et al., 2011). Some studies indicate that the right hemisphere is larger in men and the connection between left and right hemisphere is more extensive in women, whereas cerebral asymmetry is not pronounced in homosexual men, as well as women (Savic \& Lindstrom, 2008; Hines, 2011). Homosexual men and heterosexual women displayed more pronounced between-amygdala connections and greater connections with the anterior cingulate, the subcallosum, and the hypothalamus. However, the sensorimotor cortex and striatum displayed stronger connections in homosexual women and heterosexual men (Savic \& Lindstrom, 2008). The sex differences in the adolescent brain were already recognized clearly, implying the organizational effect of sex hormones and genes (Lenroot \& Giedd, 2010). It is not known whether social and environmental factors engage the same neural circuitry as underlie the effects of sex hormones and genes (Hines, 2011). 
There are several types of sexual orientation, such as heterosexual, homosexual, bisexual (Rubio-Aurioles \& Wylie, 2008). Studies and clinical practices disclosed that sexual orientation, at least in some people, is not unchangeable (Davis et al., 1996; Friedman \& Downey, 2002, 2010; Jones \& Yarhouse, 2011). Some persons who had a heterosexual or homosexual life for more than ten years became bisexual when they had to deal with tough life events at middle age (Friedman \& Downey, 2010). Here, we present two cases, whose heterosexual preference were changed in late adolescent age after a severe psychological event and successive cognitive regulation, to draw attention to the study of the possible underlying mechanism.

\section{Case Presentation}

Two cases were assessed according to the clinic practice guidelines, follow-up studies were made in case 1 for nearly 4 years by phone calls and two interviews. The study was approved by the institutional research ethics committee of the Tenth People's Hospital affiliated to Tongji University School of Medicine, and written informed consent was obtained from each subject.

Case 1: A young male, at age 24 years. He is the older identical twin of two. His mother forced him to take treatments in order to return his sexual orientation from homosexual to heterosexual, as his twin brother was heterosexual, and he had been interested in girls during his early adolescent period. At age 12 years, he fell in love with an attractive girl in his classroom. He sought any chances to contact with this girl, and wrote letters to her. But the girl did not love him, and passed his letters on to their advisor. The female advisor criticized him seriously, and slapped him across the face, and read his letters in the classroom before all of his classmates. He was astonished and repressed, and felt ashamed of being treated like this. He became timid, and realized that girls were untouchable. He gradually lost interest in girls. Meanwhile, his sexual preference changed. At age 17 years, he acknowledged that he failed to grow attracted to any girl. In contrast, he had interests in young men, although his twin brother dated a girl at that time. Since then, he has been dating several male partners, being high on samesexual activities, and his sexual preference to men has not been altered after referral to our clinic for nearly 4 years of follow-up observation. There is neither family history of psychiatric diseases, nor Axis I and Axis II diagnosis for him, in the descriptive terminology of the DSM-IV (American Psychiatric Association, 1994).

Case 2: A young female, at age 21 years. She, as a high school second-year student at age 16 years, dated a young man for 3 months, and had sexual intercourse with him. She was very sad and angry after she occasionally realized that the man had other female sexual partners. She hated his disloyal behavior, and instantly determined to end their relationship. Meanwhile, she had a definite opinion that men were un- believable. One of her girl classmate, whose parents divorced, was attracted to her at that time. She gradually became a sexual partner of the girl with various sexual activities, such as oral sex and mutual masturbation, and was satisfied with her homosexual life more than 3 years. But she felt upset and depressed, and had poor sleep in recent two months, as the relationship between her and the girl was almost broken, and she felt totally wronged by saying that she had male sex partners. She came to our clinic for relieving her depressed mood. There is neither family history of psychiatric diseases, nor DSM-IV Axis II diagnosis for her.

\section{Discussion}

Our case 1, a male identical twin, changed his heterosexual preference from girls to young men, since being suffered a serious psychological distress at age 12 years, while his twin brother maintained the heterosexuality without any change. Previous data showed familial clustering of same-sex sexual behavior (Bailey, Dunne, \& Martin, 2000; Kendler, Thornton, Gilman, \& Kessler, 2000; Santtila, Sandnabba, Harlaar, Varjonen, Alanko, \& von der Pahlen, 2008), but a new population-based study of twins, analyzed by the biometric modeling, revealed that the genetic effects were moderate or mild $(0.34-0.39$ in men and $0.18-0.19$ in women), unique environmental factors contributed much more (0.61 - 0.66 in men and $0.64-0.66$ in women) (Langstrom, Rahman, Carlstrom, \& Lichtenstein, 2010). The experience of our case 1 is concordant with this recent finding. But, it is, to some extent, different from the reports in the literature, particularly of the famous "Joan/John (one of identical male twins) case", that supported that ultimate male or female assignment decisions mainly depend upon the action of sex chromosome genes and the imprinting of prenatal testosterone (Bostwick \& Martin, 2007; Friedman, 2001).

Our two cases were young man and woman, but they changed the heterosexual preference during the adolescent period, because their primary sex desires were severely frustrated. They lost their dignity, meanwhile, had to endure the unexpectedly stressful situation. They bore great pain and distress, since the adolescent brain is very sensitive to stress (Casey, Jones, \& Somerville, 2011; Sebastian, Tan, Roiser, Viding, Dumontheil, \& Blakemore, 2011). The sexual preference was altered in the background of the psychological stress and sufferings and after a series of behavioral/cognitive reactions, such as behavioral withdrawal, reappraisal and cognitive regulation.

Many studies have demonstrated that strong acute stress and mild repeated stress cause functional and structural changes in some brain regions, such as the hippocampus, prefrontal cortex (PFC), and amygdala, that are parts of a neural circuit that plays a central role in fear conditioning and stress responsivity (McEwen, 2010). According to animal experiments, the stress caused dendritic shortening in medial prefrontal cortex and hippocampus, but produced dendritic growth in neurons in amygdala, as well as in orbitofrontal cortex (McEwen, 2010). These structure changes induced by the strong psychological stress might compromise the development of regional sexual dimorphism in the brain/sexually dimorphic brain connectivity guided by sex chromosone and sex hormones, resulting in the conversion of heterosexual orientation in some susceptible adolescents.

As the PFC, which is responsible for the higher-order cognitive regulation (Coutlee \& Huettel, 2012), is continuing to develop during adolescence and throughout the third decades of life before stabilizing at the adult level (Petanjek, Judas, Rasin, Uylings, Rakic, \& Kostovic, 2011). This results in use-dependent patterns of connectivity, and has implications for understanding the effect of environmental impact (including the psychological stress) on the development of human cognitive and emotional capacities as well as the onset of age-related behavioral manifestations (Lee \& Hoaken, 2007). The orbital PFC is primed to detect negative effect, and plays important role in the 
reappraisal (Kalisch, 2009; Kanske, Heissler, Schonfelder, Bongers, \& Wessa, 2011). The previous clinical data revealed that the operations of immature PFC in adolescents is prone to get a distorted cognitive regulation (Casey, Jones, \& Somerville, 2011; Ernst \& Korelitz, 2009; Sebastian, Tan, Roiser, Viding, Dumontheil, \& Blakemore, 2011; Sturman DA \& Moghaddam $B, 2011)$. The distorted recognition and reappraisal which possibly produced a latently converse regulation might lead susceptible adolescents changing their sexual preference against his or her physiological sex gender and primary heterosexual desires or behaviors.

In both male and female rodents, the vomeronasal system which receives pheromonal inputs was found tonically to inhibit the expression of social and reproductive innate responses typically shown by the opposite sex (Dulac \& Kimchi, 2007). Male or female mice in which the vomeronasal organ (VNO) had been surgically or genetically $\left(\mathrm{TRPC}^{-/}\right.$) ablated were found to indiscriminate courtship, or do in a complete reversal of sex-specific behavior (Dulac \& Kimchi, 2007). The mounting behavior of TRPC2 ${ }^{-1-}$ male mice was towards both males and females (Stowers, Holy, Meister, Dulac, \& Koentges, 2002), and VNO-deficient female mice attempted to copulate with other mice in a male-specific manner (Kimchi, $\mathrm{Xu}$, \& Dulac, 2007). It is worth pointing out that elimination of this pheromone-mediated sensory repression during development or adulthood results in the rapid reversal of sex-specific behavioral responses, independently from the organizational action of gonadal hormones during development (Dulac \& Kimchi, 2007). However, there is no reported evidence that human beings have active sensory neurons like those in working vomeronasal systems of other animals (Dulac \& Kimchi, 2007; Witt \& Hummel, 2006). In addition to gonadal hormones and constitutive chemosensory information, monoamine signaling is also involved in the neuromodulation. A recent study has shown that adult male mice defective in serotonin signaling lose their normal mating preference for females over males, and attempt to mate with male mice (Liu, Jiang, Si, Kim, Chen, \& Rao Y, 2011). As the strong cognitive regulation has been developed in human being, following the enlargement of newer brain areas (prefrontal cortex) (Meeks \& Jeste, 2009), some conservative neuromodulatory pathways in animals, such as vomeronasal chemosensory system, might be evolutionarily eliminated through competition, and be given place to a new mate recognition mechanism. We suppose that the PFC and related neuromodulatory factors/systems, such as gonadal hormones, adrenal stress hormones, and serotonin systems, play an important role in the development of the mate recognition mechanism, and is mainly responsible for the targeting process in human sexual orientation. The mate recognition systems which gradually built up along with the development of PFC and related neuromodulatory pathways might be vulnerable and changeable in some susceptible adolescents.

Our hypothesis is consistent with a consensus that the topdown neuromodulatory pathways play a crucial role in human in regulating behavioral decision-making (Meeks \& Jeste, 2009; Heatherton \& Wagner, 2011). The PFC and related neuromodulatory approaches let humans to effectively handle complexities and uncertainties in the environment and predict future events and make appropriate decisions (Coutlee \& Huettel, 2012; Mushtaq, Bland, \& Schaefer, 2011). Some researchers focused on the organizing effect of prenatal sex steroid hormones and the key role of hypothalamus. They insisted that sexual orientation is determined during early development, as well as the physiological gender, and left little room for learning models of sexual orientation (Garcia-Falgueras \& Swaab, 2010; Rahman, 2005; Savic, Garcia-Falgueras, \& Swaab, 2010; Swaab, 2004). However, their hypothesis is not compatible with the clinical data and genetic research findings (Davis et al., 1996; Friedman \& Downey, 2010; Joel, 2011; Langstrom, Rahman, Carlstrom, \& Lichtenstein, 2010), and our case presentation. According to the recent phylogenetic studies, there is mounting evidence that supports the roles of social learning and social recognition in determining and shaping mate choice and preferences (Kavaliers \& Choleris, 2013; Verzijden, Cate, Servedio, Kozak, Boughman, \& Svensson, 2012). Males and females of many species learn their mate preferences, and learning can take place throughout life, although sexual imprinting, which occurs at early stage of life, affecting pair formation at a much later stage in life, is seen in some birds and mammals (Verzijden, Cate, Servedio, Kozak, Boughman, \& Svensson, 2012). Human being should not be an exception. An absolute prenatal hormonal determinism is not accepted widely, but it is maintained that the hormonal prenatal milieu simply changes the threshold for the development of an appropriate psychosexuality, interacting in any case with a series of postnatal variables (Corsello et al., 2011).

Our case presentation has some limitations. First, because both patients disagreed with further examination, such as sexual and adrenal hormone test, brain imaging, and personality assessment did not carry out, corresponding data was lacking. Second, the stress and successive cognitive regulation in two adolescent cases documented retrospectively took place several years ago and no concrete data detailed the degree and the course. Third, in addition to stress and cognitive regulation, the susceptibility is also essential. Personal history, personality, executive function, family function, brain image, etc. should be studied simultaneously. All of these disadvantages have to be overcame in the future research.

In conclusion, our case presentation suggests that severe frustration of primary heterosexual desires and successive cognitive regulation might lead to reorientation of sexual preference in susceptible adolescents. The PFC and related neuromodulatory pathways may play an important role in a human mate recognition mechanism. The operations of immature PFC and related neuromodulatory pathways which are vulnerable to stress may underlie a converse regulation in these susceptible adolescents, resulting in the conversion of heterosexual orientation.

\section{Acknowledgements}

We thank Prof. Friedman at Weil Medical College, Cornell Univrsity Medical School, for providing relative literatures which are not available for us.

\section{REFERENCES}

Arnold, A. P. (2009). The organizational-activational hypothesis as the foundation for a unified theory of sexual differentiation of all mammalian tissues. Hormones and Behavior, 55, 570-578. http://dx.doi.org/10.1016/j.yhbeh.2009.03.011

Bailey, J. M., Dunne, M. P., \& Martin, N.G. (2000). Genetic and environmental influences on sexual orientation and its correlates in an Australian twin sample. Journal of Personality and Social Psychology, 78, 524-536. http://dx.doi.org/10.1037/0022-3514.78.3.524 
Bartlett, A., Smith, G., \& King, M. (2009). The response of mental health professionals to clients seek help to change or redirect samesex sexual orientation. BMC Psychiatry, 9, 1-8.

Berenbaum, S. A., \& Beltz, A. M. (2011). Sexual differentiation of human behavior: Effects of prenatal and pubertal organizational hormones. Frontiers in Neuroendocrinology, 32, 183-200.

http://dx.doi.org/10.1016/j.yfrne.2011.03.001

Blecher, S. R., \& Erickson, R. P. (2007). Genetics of sexual development: A new paradigm. American Journal of Medical Genetics Part A, 143A, 3054-3068. http://dx.doi.org/10.1002/ajmg.a.32037

Bocklandt, S., \& Vilain, E. (2007). Sex differences in brain and behavior: hormones versus genes. Advances in Genetics, 59, 245-266. http://dx.doi.org/10.1016/S0065-2660(07)59009-7

Bostwick, J. M., \& Martin, K. A. (2007). A man's brain in an ambiguous body: A case of mistaken gender identity. The American Journal of Psychiatry, 164, 1499-1505.

http://dx.doi.org/10.1176/appi.ajp.2007.07040587

Casey, B., Jones, R. M., \& Somerville, L. H. (2011). Braking and accelerating of the adolescent brain. Journal of Research on Adolescence., 21, 21-33. http://dx.doi.org/10.1111/j.1532-7795.2010.00712.x

Colapinto, J. (2000). As nature made him: The boy who was raised as a girl. New York: Harper Collins.

Corsello, S. M., Di Donna, V., Senes, P., Luotto, V., Ricciato, M. P., Paragliola, R. M. et al. (2011). Biological aspects of gender disorders. Minerva Endocrinologica, 36, 325-339.

Coutlee, C. G., \& Huettel, S. A. (2012). The functional neuroanatomy of decision making: Prefrontal control of thought and action. Brain Research, 1428, 3-12. http://dx.doi.org/10.1016/j.brainres.2011.05.053

Davis, R. M., Genel, M., Howe, J. P., Karlan, M. S., Kennedy, W. R., Numann, P. J. et al. (1996). Health care needs of gay men and lesbians in the United States. The Journal of the American Medical Association, 275, 1354-1359. http://dx.doi.org/10.1001/jama.1996.03530410068036

DiNapoli, L., \& Capel, B. (2008). SRY and standoff in sex determination. Molecular Endocrinology, 22, 1-9. http://dx.doi.org/10.1210/me.2007-0250

Dulac, C., \& Kimchi, T. (2007). Neural mechanisms underlying sexspecific behaviors in vertebrates. Current Opinion in Neurobiology, 17, 675-683. http://dx.doi.org/10.1016/j.conb.2008.01.009

Ernst, M., \& Korelitz, K. E. (2009). Cerebral maturation in adolescence: Behavioral vulnerability. L'Encéphale, 35, S182-S189. http://dx.doi.org/10.1016/S0013-7006(09)73469-4

Friedman, R. C., \& Downey, J. I. (2002). Sexual orientation and psychoanalysis (pp. 225-263). New York: Columbia University Press.

Friedman, R. C., \& Downey, J. I. (2010). Psychotherapy of bisexual men. The Journal of the American Academy of Psychoanalysis and Dynamic Psychiatry, 38, 181-197.

http://dx.doi.org/10.1521/jaap.2010.38.1.181

Garcia-Falgueras, A., \& Swaab, D. F. (2010). Sexual hormones and the brain: an essential alliance for sexual identity and sexual orientation. Endocrine Reviews, 17, 22-35. http://dx.doi.org/10.1159/000262525

Heatherton, T. F., \& Wagner, D. D. (2011). Cognitive neuroscience of self-regulation failure. Trends in Cognitive Sciences, 15, 132-139. http://dx.doi.org/10.1016/j.tics.2010.12.005

Herbert, J. (2008). Who do we think we are? The brain and gender identity. Brian, 131, 3115-3117.

http://dx.doi.org/10.1093/brain/awn257

Hines, M. (2011). Gender development and the human brain. Annual Review of Neuroscience, 34, 69-88. http://dx.doi.org/10.1146/annurev-neuro-061010-113654

Joel, D. (2011). Male or female? Brains are Intersex. Frontiers in Integrative Neuroscience, 5, 1-5. http://dx.doi.org/10.3389/fnint.2011.00057

Jones, S. L., \& Yarhouse, M. A. (2011). A longitudinal study of attempted religiously mediated sexual orientation change. Journal of Sex \& Marital Therapy, 37, 404-427. http://dx.doi.org/10.1080/0092623X.2011.607052

Kalisch, R. (2009). The functional neuroanatomy of reappraisal: Time matters. Neuroscience \& Biobehavioral Reviews, 33, 1215-1226. http://dx.doi.org/10.1016/j.neubiorev.2009.06.003

Kanske, P., Heissler, J., Schönfelder, S., Bongers, A., \& Wessa, M. (2011). How to regulate emotion? Neural networks for reappraisal and distraction. Cerebral Cortex, 21, 1379-1388. http://dx.doi.org/10.1093/cercor/bhq216

Kavaliers, M., \& Choleris, E. (2013). Neurobiological correlates of sociality, mate choice and learning. Trends in Ecology \& Evolution, 28, 4-5. http://dx.doi.org/10.1016/j.tree.2012.08.019

Kendler, K. S., Thornton, L. M., Gilman, S. E., \& Kessler, R. C. (2000). Sexual orientation in a US national sample of twin and nontwin sibling pairs. The American Journal of Psychiatry, 157, 1843-1846. http://dx.doi.org/10.1176/appi.ajp.157.11.1843

Kimchi, T., Xu, J., \& Dulac, C. (2007). A functional circuit underlying male sexual behaviour in the female mouse brain. Nature, 448, 10091015. http://dx.doi.org/10.1038/nature06089

Langstrom, N., Rahman, Q., Carlstrom, E., \& Lichtenstein, P. (2010). Genetic and environmental effects on same-sex sexual behavior: a population study of twins in Sweden. Archives of Sexual Behavior, 39, 75-80. http://dx.doi.org/10.1007/s10508-008-9386-1

Lee, V., \& Hoaken, P. N. S. (2007). Cognition, emotion, and neurobiological development: Mediating the relation between maltreatment and aggression. Child Maltreatment, 12, 281-298.

http://dx.doi.org/10.1177/1077559507303778

Lenroot, R. K., \& Giedd, J. N. (2010). Sex differences in the adolescent brain. Brain and Cognition, 72, 46-55. http://dx.doi.org/10.1016/j.bandc.2009.10.008

Liu, Y., Jiang, Y., Si, Y., Kim, J. Y., Chen, Z. F., \& Rao, Y. (2011). Molecular regulation of sexual preference revealed by genetic studies of 5-HT in the brains of male mice. Nature, 472, 95-99. http://dx.doi.org/10.1038/nature09822

McEwen, B. S. (2010). Stress, sex, and neural adaptation to a changing environment: Mechanisms of neuronal remodeling. Annals of the New York Academy of Sciences, 1204, E38-E59. http://dx.doi.org/10.1111/j.1749-6632.2010.05568.x

Meeks, T. W., \& Jeste, D. V. (2009). Neurobiology of wisdom: A literature overview. Archives of General Psychiatry, 66, 355-365. http://dx.doi.org/10.1001/archgenpsychiatry.2009.8

Mushtaq, F., Bland, A. R., \& Schaefer, A. (2011). Uncertainty and cognitive control. Frontiers in Psychology, 2, 1-10.

Petanjek, Z., Judas, M. S., Rasin, M. R., Uylings, H. B., Rakic, P., \& Kostovic, I. (2011). Extraordinary neoteny of synaptic spines in the human prefrontal cortex. Proceedings of the National Academy of Sciences of the United States of America, 108, 13281-13286. http://dx.doi.org/10.1073/pnas.1105108108

Rahman, Q. (2005). The neurodevelopment of human sexual orientation. Neuroscience \& Biobehavioral Reviews, 29, 1057-1066. http://dx.doi.org/10.1016/j.neubiorev.2005.03.002

Rubio-Aurioles, E., \& Wylie, K. (2008). Sexual orientation matters in sexual medicine. The Journal of Sexual Medicine, 5, 1521-1533. http://dx.doi.org/10.1111/j.1743-6109.2008.00903.x

Santtila, P., Sandnabba, N. K., Harlaar, N., Varjonen, M., Alanko, K., von der Pahlen, B. (2008). Potential for homosexual response is prevalent and genetic. Biological Psychology, 77, 102-105. http://dx.doi.org/10.1016/j.biopsycho.2007.08.006

Savic, I., \& Lindstrom, P. (2008). PET and MRI show differences in cerebral asymmetry and functional connectivity between homo- and heterosexual subjects. Proceedings of the National Academy of Sciences of the United States of America, 108, 13281-13286.

Savic, I., Garcia-Falgueras, A., \& Swaab, D. F. (2010). Sexual differentiation of the human brain in relation to gender identity and sexual orientation. Progress in Brain Research, 186, 41-62. http://dx.doi.org/10.1016/B978-0-444-53630-3.00004-X

Sebastian, C. L., Tan, G. C., Roiser, J. P., Viding, E., Dumontheil, I., \& Blakemore, S. J. (2011). Developmental influences on the neural bases of responses to social rejection: Implications of social neuroscience for education. Neuroimage, 57, 686-694. http://dx.doi.org/10.1016/j.neuroimage.2010.09.063

Stowers, L., Holy, T. E., Meister, M., Dulac, C., \& Koentges G. (2002). Loss of sex discrimination and male-male aggression in mice defi- 


\section{B. G. ZHU ET AL.}

cient for TRP2. Science, 295, 1493-1500

http://dx.doi.org/10.1126/science.1069259

Sturman, D. A., \& Moghaddam, B. (2011). The neurobiology of adolescence: Changes in brain architecture, functional dynamics, and behavioral tendencies. Neuroscience \& Biobehavioral Reviews, 35, 1704-1712. http://dx.doi.org/10.1016/j.neubiorev.2011.04.003

Swaab, D. F. (2004). Sexual differentiation of the human brain: Relevance for gender identity, transsexualism and sexual orientation. Gynecological Endocrinology, 19, 301-312.

http://dx.doi.org/10.1080/09513590400018231
Verzijden, M. N., Cate, C., Servedio, M. R., Kozak, G. M., Boughman, J. W., \& Svensson, E. I. (2012). The impact of learning on sexual selection and speciation. Trends in Ecology \& Evolution, 27, 511-519. http://dx.doi.org/10.1016/j.tree.2012.05.007

Witt, M., \& Hummel, T. (2006). Vomeronasal versus olfactory epithelium: Is there a cellular basis for human vomeronasal perception? International Review of Cytology, 248, 209-259.

http://dx.doi.org/10.1016/S0074-7696(06)48004-9 